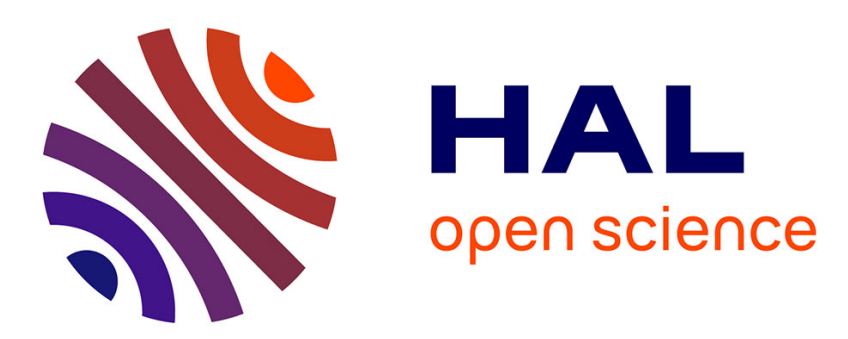

\title{
Comparative QTL analysis of salinity tolerance in terms of fruit yield using two solanum populations of F7 lines
}

\author{
Irene Villalta, G. P Bernet, E. Carbonell, M. J Asins
}

\section{To cite this version:}

Irene Villalta, G. P Bernet, E. Carbonell, M. J Asins. Comparative QTL analysis of salinity tolerance in terms of fruit yield using two solanum populations of F7 lines. TAG Theoretical and Applied Genetics, 2007, 114 (6), pp.1001-1017. 10.1007/s00122-006-0494-9 . hal-02140578

\section{HAL Id: hal-02140578 \\ https://hal.science/hal-02140578}

Submitted on 8 Nov 2019

HAL is a multi-disciplinary open access archive for the deposit and dissemination of scientific research documents, whether they are published or not. The documents may come from teaching and research institutions in France or abroad, or from public or private research centers.
L'archive ouverte pluridisciplinaire HAL, est destinée au dépôt et à la diffusion de documents scientifiques de niveau recherche, publiés ou non, émanant des établissements d'enseignement et de recherche français ou étrangers, des laboratoires publics ou privés. 


\title{
Comparative QTL analysis of salinity tolerance in terms of fruit yield using two solanum populations of $F_{7}$ lines
}

\author{
I. Villalta · G. P. Bernet $\cdot$ E. A. Carbonell $\cdot$ M. J. Asins
}

Received: 16 June 2006 / Accepted: 21 December 2006 / Published online: 14 February 2007

(C) Springer-Verlag 2007

\begin{abstract}
Salt tolerance has been analysed in two populations of $\mathrm{F}_{7}$ lines developed from a salt sensitive genotype of Solanum lycopersicum var. cerasiforme, as female parent, and two salt tolerant lines, as male parents, from S. pimpinellifolium, the $\mathrm{P}$ population (142 lines), and $S$. cheesmaniae, the C population (116 lines). Salinity effects on 19 quantitative traits including fruit yield were investigated by correlation, principal component analysis, ANOVA and QTL analysis. A total of 153 and 124 markers were genotyped in the $P$ and $\mathrm{C}$ populations, respectively. Some flowering time and salt tolerance candidate genes were included. Since most traits deviated from a normal distribution, results based on the Kruskal-Wallis non-parametric test were preferred. Interval mapping methodology and ANOVA were also used for QTL detection. Eight out of 15 QTLs at each population were detected for the target traits under both control and high salinity conditions, and among them, only average fruit weight (FW) and fruit number (FN) QTLs (fw1.1, fw2.1 and fn1.2) were detected in both populations. The individual contribution of QTLs were, in general, low. After leaf chloride concentration, flowering time is the trait most affected by salinity because different QTLs are detected and some of their QTL $\times$ E interactions have been found significant. Also reinforcing the interest on information provided by QTL analysis, it has been
\end{abstract}

Communicated by C. Hackett.

I. Villalta · G. P. Bernet · E. A. Carbonell · M. J. Asins ( $\square)$

Instituto Valenciano de Investigaciones Agrarias,

Apdo. Oficial, 46113 Moncada (Valencia), Spain

e-mail:mjasins@ivia.es found that non-correlated traits may present QTL(s) that are associated with the same marker. A few salinity specific QTLs for fruit yield, not associated with detrimental effects, might be used to increase tomato salt tolerance. The beneficial allele at two of them, fw8.1 (in C) and $t w 8.1$ (for total fruit weight in P) corresponds to the salt sensitive parent, suggesting that the effect of the genetic background is crucial to breed for wide adaptation using wild germplasm.

\section{Introduction}

Soil salinization, the concentration of salts in the surface or near-surface, is a major process of land degradation, leading to falling crop yields and the loss of land for production in a wide range of environments. Human induced salinization also contributes to the desertification process in the world's drylands and temperate environments because it is particularly associated with irrigation schemes (Thomas and Middleton 1993). Besides, there is a growing problem of competition for soft water utilization among urban, industrial and agricultural sectors, especially in semi-arid regions.

Breeding for salt tolerance has been recognized as a suitable approach to improve crop productivity in saltaffected areas. However, in spite of the great effort devoted to this objective, only a small number of cultivars, partially tolerant to salinity, have been developed (Owen et al. 1994; Al-Doss and Smith 1998; Dierig et al. 2001; Steiner and Banuelos 2003). Two major problems are encountered: the definition, or selection criteria, for salt tolerance and the efficient use of the wild germplasm to increase the salt tolerance of the crop. 
Tomato (Solanum lycopersicum L.) is a good crop model to genetically interrelate the physiology and agronomy involved in the adaptation to a broad range of salinity level for three reasons. First, its genetics is better known than any other dicotyledonous crop; second, it presents a rich wild germplasm pool and third, it can be transformed by different methods. In addition, the physiology of tomato in saline and non-saline conditions has been extensively studied providing a valuable basis to understand the responses of the plants to cultural practices (Cuartero et al. 2006).

Although there are salt tolerant relatives to the cultivated tomato, it is difficult to enrich elite lines with genes from wild species conferring tolerance. The main difficulties come from, in theory, the large number of genes involved, most of them with small effects, and the high costs of recovering the genetic background of the receptor cultivar. Conventional breeding programmes to improve salt tolerance of elite genotypes using wild species as donors are inefficient at the selection stages. Can Quantitative Trait Loci (QTLs) analysis of salt tolerance provide the necessary information to find an efficient breeding strategy using wild relatives?

In the case of crop plants, it is ultimately the yield of new plants under specific field conditions that will determine whether or not a specific gene or metabolic or signalling pathway is of technological importance. In a previous study, we compared QTLs involved in the salt tolerance, in terms of fruit yield, of three $F_{2}$ families derived from crosses of the tomato cultivated species (Solanum lycopersicum L.) and two wild species $S$. pimpinellifolium L. and S. cheesmaniae (L. Riley) Fosberg (Monforte et al. 1997a, b). Nevertheless, breeding for salt tolerance requires breeding for a wide adaptation to different salinity levels, because salinity is an abiotic stress factor that varies in time and space. Since the possibilities to study the genetics and physiology of adaptation to different salinity levels in terms of $\mathrm{G} \times \mathrm{E}$ interaction were found to be very limited in $\mathrm{F}_{2}$ populations, we have developed and genetically characterized two populations of RILs derived from those $F_{2}$ populations (Villalta et al. 2005). In spite of the advantages using RIL populations in QTL analysis of complex traits, these kinds of studies are certainly scarce (Goldman et al. 1995; Saliba-Colombani et al. 2001) and need to be tested. The objective of the present work was to carry out a comparative QTL analysis of tomato fruit yield under both saline and non-saline irrigation conditions of two populations of $\mathrm{F}_{7}$ lines searching for an efficient utilization of wild salt tolerant germplasm.

\section{Materials and methods}

Plant material and growing conditions

Two populations of $\mathrm{F}_{7}$ lines were developed from a salt sensitive genotype Solanum lycopersicum var. cerasiforme (formerly L. esculentum) as female parent. Male parents were two salt tolerant lines from $S$. pimpinellifolium L. (formely L. pimpinellifolium) for the P population, and $S$. cheesmaniae (L. Riley) Fosberg (formerly L. cheesmanii) for the C population, respectively. Both populations were developed by single seed descent from 300 and 400 individual plants of the $\mathrm{P}$ and $\mathrm{C} \mathrm{F}_{2}$ progenies, respectively (Monforte et al. 1997b) after five selfings, with no conscious selection at any generation, under greenhouse or screenhouse conditions. One hundred and forty-two $\mathrm{F}_{7} \mathrm{P}$ lines and $116 \mathrm{~F}_{7}$ $\mathrm{C}$ lines were used for the salinity tolerance experiments here reported.

Experiments were carried out in Valencia, Spain, in the growing periods May-December (2001) and January-November (2002) for the $\mathrm{P}$ and C populations, respectively. Each plant was cultivated in an individual pot $(3.5 \mathrm{l})$ in a greenhouse at $25 \pm 10^{\circ} \mathrm{C}$. Plants under saline treatment were grown on sand and irrigated with one half Hoagland solution plus $\mathrm{NaCl}(150 \mathrm{mM})(15 \mathrm{dS} / \mathrm{m}, \mathrm{pH} 7.5) . \mathrm{NaCl}$ concentration was increased gradually 1 day after transplanting $(6,8,12,14$ and $15 \mathrm{dS} / \mathrm{m})$, until the final conductivity of treatment was attained, two weeks after transplanting. Plants under near optimal conditions (control) were grown in peat plus sand and irrigated with tap water $(0.3 \mathrm{dS} / \mathrm{m}, \mathrm{pH}$ 6.9) trying to follow the same procedure as with the previous $F_{2}$ populations (Monforte et al. 1997b). All plants were fertilized once a week with $200 \mathrm{ml}$ of 1:75 dilution of the following solution: $\mathrm{MgSO}_{4}\left(2.08 \times 10^{-3} \mathrm{M}\right)$, $\mathrm{NH}_{4} \mathrm{H}_{2} \mathrm{PO}_{4}\left(4.35 \times 10^{-3} \mathrm{M}\right), \mathrm{KNO}_{3}\left(4.95 \times 10^{-3} \mathrm{M}\right)$ and micronutrient mixture Welgro Micromix $(0.25 \mathrm{~g} / \mathrm{l})$.

Experimental design and trait evaluation

A completely randomized factorial design was used with three replicates per combination line-treatment resulting in a total of 852 plants for $\mathrm{P}$ population and 696 plants for $\mathrm{C}$ population. For principal component and QTL analyses, the three replications were averaged. Nineteen quantitative traits were measured for each individual plant until the sixth week of fruit production: 
- Total fruit weight per plant (g) (TW), measured as the total weight of fruits collected per plant during six weeks of production.

- Fruit number per plant (FN), measured as the number of fruits produced per plant during six weeks of production.

- Average fruit weight (g) (FW), measured as the mean fruit weight of all fruits produced per plant until the sixth week of production.

- Stem diameter (mm) (SD) eight weeks after transplanting, measured in the immediate area under the fist node.

- Stem length (cm) (SL), six weeks after transplanting.

- Number of leaves up to the first flower (NL).

- Number of flowers per truss (FL), number of fruits per truss (FR) and fruit set percentage per truss (FS) were measured all in the same first representative truss. First trusses, which bear less than four flowers and are generally sterile, were discarded.

- Number of days from sowing date till flowering date $(\mathrm{SF})$, i.e. when the fist opened flower appeared in the fist truss.

- Number of days from sowing date till harvesting date $(\mathrm{SH})$, i.e. when the first ripe fruit appeared in the first truss.

- Number of days from flowering date till harvesting date $(\mathrm{FH})$ was considered as the difference between $\mathrm{SH}$ and SF.

- Fresh root weight (g) (FRW), of plants at the end of the experiment.

- $\mathrm{Cl}^{-}$concentration $(\mathrm{mg} / \mathrm{L})(\mathrm{Cl})$ was measured after three months of treatment. Five to six young developing leaves around the apical meristem were collected and dried, subsequent chloride analysis were carried out as described by in Gilliam (1971) using a Sherwood chloride analyser 926.

- Leaf colour parameters were estimated after three months of treatment only in $\mathrm{P}$ population; measures were taken per triplicate in the third and fourth leave and averaged per plant using a Minolta colorimeter CR-200. Colour space is defined by Hunter coordinates ( $\mathrm{L}, \mathrm{a}, \mathrm{b})$, where "a" represent from negative to positive values the colour scale from green to red, "b" represent the colour scale from blue to yellow and L represent luminosity.

- Dry root weight (g) (DRW) and Root water content $(\mathrm{F}-\mathrm{D})$, measured as the difference between FRW and DRW, were measured only in $\mathrm{C}$ population. FRW was evaluated in both populations at the end of each experiment.
Statistical analysis and heritability estimation

Broad sense heritability $\left(h_{\mathrm{S}}^{2}\right)$ was calculated for traits measured in both populations assuming individuals from the sixth self-pollination generation were nearly homozygous for all loci. Heritability for each treatment was calculated using the formula: $h_{\mathrm{S}}^{2}=V_{\mathrm{g}} /\left(V_{\mathrm{g}}+V_{\mathrm{e}}\right)$ where $V_{\mathrm{g}}$ and $V_{\mathrm{e}}$ are the estimates of genotype and environmental variance, respectively, by MIVQUE (Minimum Variance Quadratic Unbiased Estimator).

The effects of the line (genotype), treatment and $\mathrm{G} \times \mathrm{E}$ interaction on each quantitative trait were analysed using factorial two-way ANOVA. The following linear model was applied: $Y_{i j k}=\mu+\alpha_{i}+\beta_{j}+(\alpha \beta)_{i j}+$ $\varepsilon_{i j k}$, where $Y_{i j k}$ is the trait value for plant $k$ on line $i$ and treatment $j ; \mu$ is the general mean; $\alpha_{i}$ is the effect of line $i ; \beta_{j}$ is the effect of treatment $j ;(\alpha \beta)_{i j}$ is the effect of the interaction of line $i$ and treatment $j$ and $\varepsilon_{i j k}$ is the effect of plant $k$ from the combination of line $i$ and treatment $j ; \varepsilon_{i j k}$ represents the error term.

Pearson's correlation coefficients were calculated for each trait combination in both populations under control and saline conditions.

Standardized data was used for principal component analysis (PCA). The Infostat statistical package (Infostat 2004) was used to determine the two dimensional trait distribution under control and saline treatment in both populations.

\section{Marker and QTL analysis}

Marker analyses and linkage maps used for the QTL analysis have been previously reported by Villalta et al. (2005). Nevertheless, some additional, candidate genes have been added to those maps for the present study such as the flowering time candidates (Ausín et al, 2005) falsiflora, the tomato orthologue of leafy from Arabidopsis (LEFA_550) and Phytocrome B2 (PhyB2). Their sequences, available at National Center for Biotechnology Information (http://www.ncbi.nlm.nih.gov/ blast), were used for primer design. The identity of the polymorphic amplification products were checked by sequence analysis. Other markers, developed from salt tolerance candidate genes (STC1 to STC5) were also mapped for the QTL analysis. A total of 153 markers were genotyped for the $\mathrm{P}$ population and 124 markers for the $\mathrm{C}$ using DNA pools of 6 plants per line. New linkage analyses were calculated using Joinmap 3.0 software for Windows (Van Ooijen and Voorrips 2001). A minimum LOD of 3 was set as a threshold to create linkage groups using a recombination fraction of 0.5 for linkage analysis. Kosambi function (Kosambi 1994) was 
used to order markers, and to estimate interval distances.

Single marker analyses were performed using ANOVA (AN) and Kruskal-Wallis (KW) tests to identify molecular markers significantly associated with each trait under saline and control conditions. The choice of analysis AN or KW was based on the results of the Kolmogorov-Smirnov normality test for trait distribution using the residuals from ANOVA. Analyses were carried out either ignoring (heterozygotes as missing data) or considering the heterozygote marker class for codominant markers (three genotypes per marker) in order to study possible effects of dominance deviation at each QTL. Only those putative QTLs detected at $P \leq 0.01$ were considered. When two or more collinear markers were significantly associated with a particular trait only the marker (or markers) showing the lowest $P$ value was chosen, thus all reported QTLs had $P \leq 0.0068$. Additional QTL analyses were carried out using interval mapping procedure using MapQTL (Van Ooijen and Maliepaard 1996). Only LOD values larger than 1.75 are reported. Permutation tests were used to obtain an overall 5\% significant level for each linkage group. QTL $\times \mathrm{E}$ effects of only putative QTLs have been studied by ANOVA and by interval mapping using QTL-Cartographer (Basten et al. 2002).

\section{Results}

From all studied traits, we will focus on those related directly or indirectly to fruit yield since tolerance to salinity is studied in this work as the plant adaptability to this abiotic factor in terms of fruit yield.

\section{Trait correlation and principal component analyses}

Table 1 summarizes the significant $(P<0.05)$ correlations between traits, in both populations, under control and saline conditions. As expected, the correlations between TW and its components FN and FW were amongst the most important positive correlations in both populations. In the $\mathrm{P}$ population the highest correlations were detected between FN and FR in both control $(r=0.71)$ and saline $(r=0.65)$ conditions. These correlations were less evident in the C population, where the highest correlations were between FN and TW, and between FN and FS under control and saline conditions, respectively.

Time until flowering (SF) was negatively correlated with FN and TW regardless of treatment and population. Among the traits evaluated before flowering, only
SL is significantly associated with yield traits (TW and FN) in both populations, although only under salinity. Note that SF shows the highest correlation coefficient with SL.

The first two components extracted by the PCA explained about $40 \%$ of the total variance, in the four combinations of population and treatment (Fig. 1). In all four cases, the first component is clearly explained by two groups of traits: FN, FR, FS and TW on the right, and earliness traits (SF, NL, SH, FH) on the left.

\section{Variance components and heritability estimation}

Table 2 summarizes MIVQUE variance components, genetic variance $\left(V_{\mathrm{g}}\right)$ and environmental variance $\left(V_{\mathrm{e}}\right)$ that were used for heritability estimation. The significance of the treatment effect $(\mathrm{E})$, its direction from control to salinity condition $(\mathrm{c} \rightarrow \mathrm{s})$ and the genotype by environment interaction $(\mathrm{G} \times \mathrm{E})$ are also indicated. Genotypic effect was always significant in both populations at $P<0.001$ except for $\mathrm{FH}$ in the $\mathrm{C}$ population which was only significant at $P<0.01$ (data not shown), revealing the high level of genetic variation for all traits in both populations.

Salinity had a significant effect in most traits, especially in the $\mathrm{C}$ population, delaying flowering and reducing yield (mainly FW), SD, SL and FL. In the $\mathrm{P}$ population the effect of salinity on FN and FRW is not significant. However, the significant $\mathrm{G} \times \mathrm{E}$ interaction for FN suggest that under salinity, the number of fruits either increases or decreases depending on the genotype.

The estimates of trait heritability did not show large differences between populations, although, comparatively, more traits presented heritabilities over 0.50 in the $\mathrm{C}$ population. Estimates range from $0(\mathrm{Cl}$ in $\mathrm{C}$, under control condition) to 0.82 (FW in $\mathrm{C}$, under control condition). In general, heritability values are higher under salinity in the $\mathrm{P}$ population while in the $\mathrm{C}$ population this tendency is not so generalized mostly due to the drop in genetic variability, such as for FW.

\section{QTL analysis}

Putative QTLs for yield related traits, flowering related traits and $\mathrm{Cl}^{-}$content in young leaves are presented in Table 3. Their map positions are shown in Fig. 2.

In order to have a general indication of the threshold $P$ values to be used in the statistical tests, 1,000 permutation tests per population, trait and treatment were run using MapQTL. For the $\mathrm{P}$ population, in a per linkage group test, the highest critical LOD value for the different traits was 1.8 what implied a likelihood 


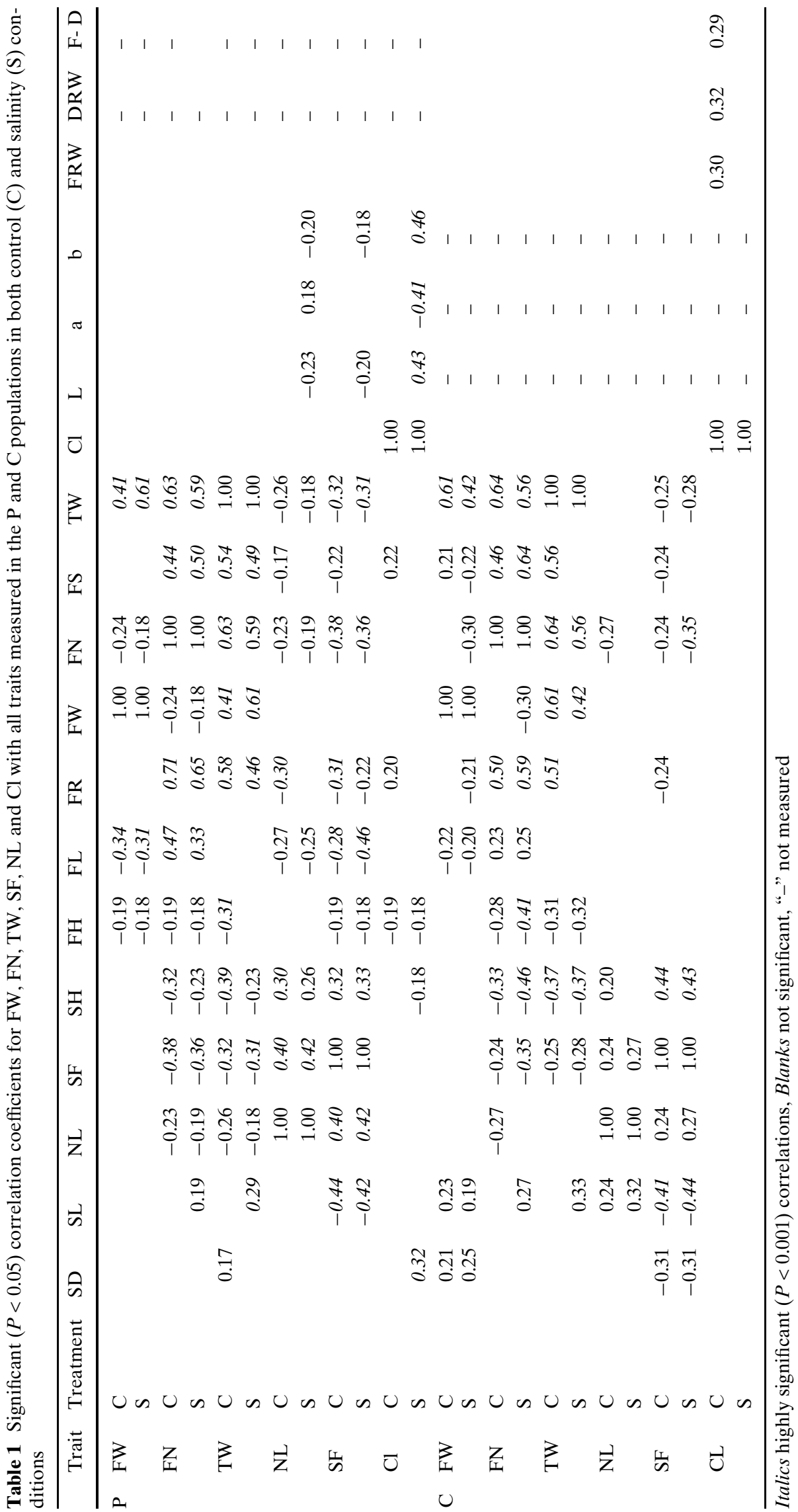



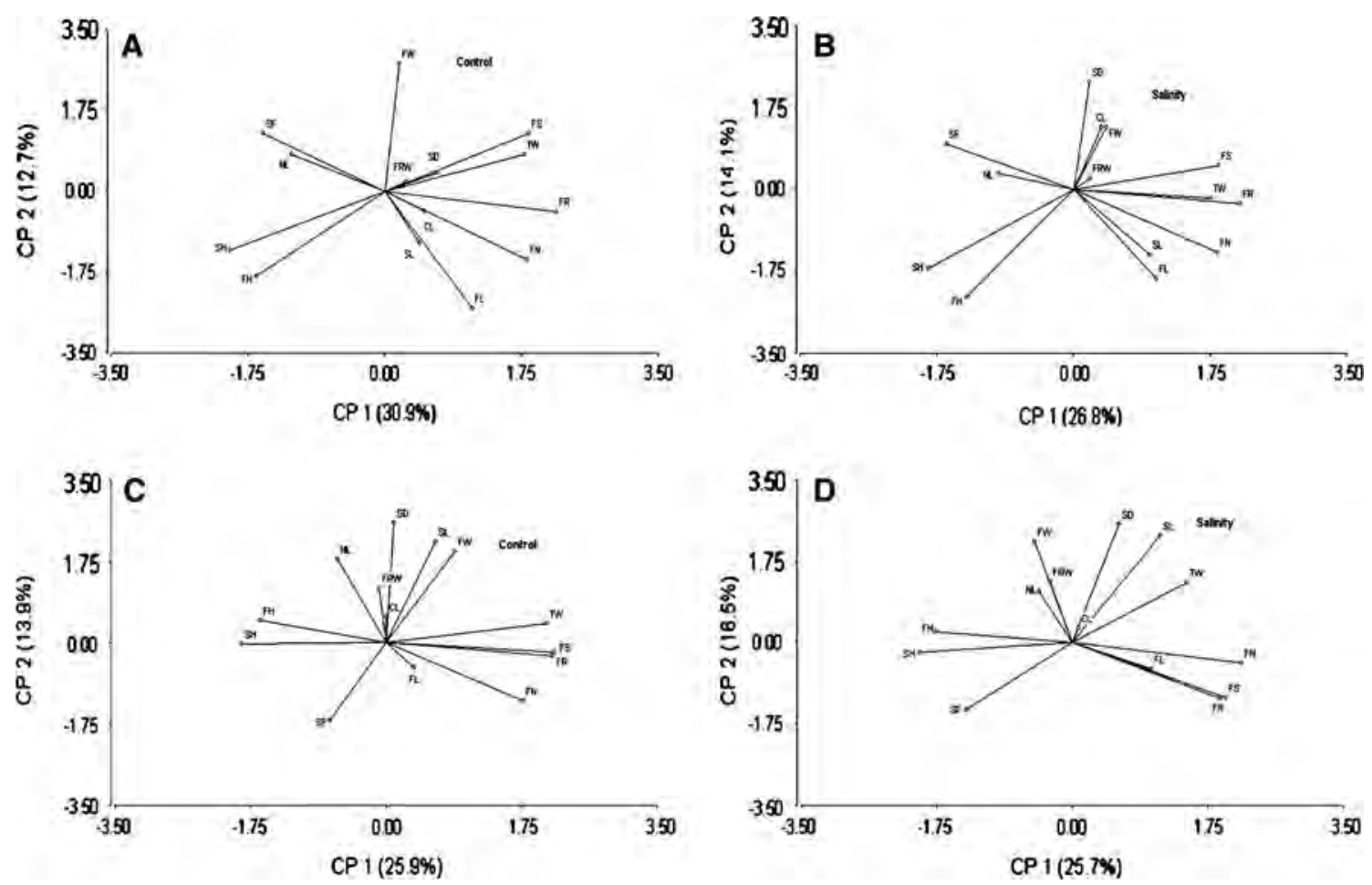

Fig. 1 Principal plane for the traits in the $\mathrm{P}(\mathbf{a}$ and $\mathbf{b})$ and the $\mathrm{C}(\mathbf{c}$ and $\mathbf{d})$ populations under control (a and $\mathbf{c})$ and high salinity (b and d) conditions

ratio test of 8.29. The $P$ values associated with the chi-square distribution for 2 degrees of freedom (3 genotypes) or 1 degree of freedom (2 genotypes) were 0.004 and 0.016 , respectively. Similarly, in the C population, the $P$ values associated with the chisquare distribution were 0.005 and 0.020 depending on the number of degrees of freedom. Only two traits, $\mathrm{Cl}$ and $\mathrm{NL}$, displayed a normal distribution in both populations, and also SF under control condition in the $\mathrm{P}$ population. Hence, results for these traits using the ANOVA and interval mapping (based on the chi-square approximation) methodologies are comparable. The $P$ values for all other variables in Table 3 correspond to the Kruskal-Wallis non-parametric test because they deviate from a normal distribution.

Significant QTLs detected by AN or KW were identified for all six traits (FW, FN, TW, Cl, SF, and NL) ranging from 1 to 9 QTLs per trait and population. Comparing the $\mathrm{P}$ and $\mathrm{C}$ populations, two QTLs were considered to be potentially the same locus if they mapped to the same $10 \mathrm{cM}$ region. In the $\mathrm{P}$ population 15 QTL under control and 15 QTL under saline conditions were detected. A similar number of QTLs were detected in the $\mathrm{C}$ population (15 and 16 under control and saline conditions, respectively). Only eight QTLs in each population were detected under both condi- tions. Among them, fw1.1, fw2.1 and fn1.2 were detected in both populations. At the chosen significance level, no QTL for the target trait was detected in chromosome 9. For some QTLs (specially those involved in $\mathrm{Cl}^{-}$leaf concentration), lines with heterozygotes at the associated marker showed a trait mean superior or inferior to any homozygous line, suggesting the presence of heterotic effects.

None of the detected Cl QTLs under salinity seems to be common between wild species, therefore a minimum of six QTLs are controlling $\mathrm{Cl}^{-}$concentration in leaves when it is in excess in the nutrient solution. In this case, the wild allele is always associated with a lower $\mathrm{Cl}^{-}$concentration in the $\mathrm{P}$ population while in the $\mathrm{C}$ population, the wild allele is associated with a lower $\mathrm{Cl}^{-}$concentration for only one of the three $\mathrm{Cl}$ QTLS.

A minimum of six FN QTLs have been detected. One of them (fn1.2), co-locates with FW QTLs in both populations accordingly with the negative correlation found between these two traits. One FN QTL in the $\mathrm{P}$ and two in the $\mathrm{C}$ population, are detected under both conditions being fn1.2 the only FN QTL common between populations and treatments. In all cases, the wild allele increases the total number of fruits. Only fn10.1 from the P population is salinityspecific. 
Table 2 Genetic $\left(V_{\mathrm{g}}\right)$ and environmental $\left(V_{\mathrm{e}}\right)$ variance components used for the estimation of broad sense heritability $\left(h_{\mathrm{S}}^{2}\right)$ in the $\mathrm{P}$ and C populations

\begin{tabular}{|c|c|c|c|c|c|c|c|c|c|c|c|c|c|}
\hline \multirow[t]{2}{*}{ Trait } & \multirow[t]{2}{*}{ Treatment } & \multicolumn{6}{|l|}{$\mathrm{P}$} & \multicolumn{6}{|l|}{$\mathrm{C}$} \\
\hline & & $V_{\mathrm{g}}$ & $V_{\mathrm{e}}$ & $h_{\mathrm{S}}^{2}$ & $\mathrm{E}$ & $\mathrm{c} \rightarrow \mathrm{s}$ & $\mathrm{G} \times \mathrm{E}$ & $V_{\mathrm{g}}$ & $V_{\mathrm{e}}$ & $h_{\mathrm{S}}^{2}$ & $\mathrm{E}$ & $\mathrm{c} \rightarrow \mathrm{s}$ & $\mathrm{G} \times \mathrm{E}$ \\
\hline \multirow[t]{2}{*}{ SD } & $\mathrm{C}$ & 0.73 & 1.10 & 0.40 & $* * *$ & $\downarrow$ & $* * *$ & 0.98 & 0.78 & 0.56 & $* * *$ & $\downarrow$ & $* * *$ \\
\hline & $\mathrm{S}$ & 0.67 & 0.85 & 0.44 & & & & 0.63 & 0.64 & 0.50 & & & \\
\hline \multirow[t]{2}{*}{ FL } & $\mathrm{C}$ & 12.93 & 9.11 & 0.59 & $* *$ & $\downarrow$ & $* * *$ & 5.41 & 4.78 & 0.53 & $* * *$ & $\downarrow$ & $* *$ \\
\hline & $\mathrm{S}$ & 10.18 & 6.06 & 0.63 & & & & 2.24 & 2.22 & 0.50 & & & \\
\hline \multirow[t]{2}{*}{ TW } & $\mathrm{C}$ & 238.55 & 245.80 & 0.49 & $* * *$ & $\downarrow$ & $* * *$ & 368.17 & 367.10 & 0.50 & $* * *$ & $\downarrow$ & $* * *$ \\
\hline & $S$ & 187.19 & 164.13 & 0.53 & & & & 23.35 & 58.90 & 0.28 & & & \\
\hline \multirow[t]{2}{*}{ FN } & $\mathrm{C}$ & 43.03 & 43.61 & 0.50 & & & $* * *$ & 77.33 & 47.38 & 0.62 & $* * *$ & $\downarrow$ & $* * *$ \\
\hline & $\mathrm{S}$ & 51.05 & 45.55 & 0.53 & & & & 19.85 & 17.54 & 0.53 & & & \\
\hline \multirow[t]{2}{*}{$\mathrm{Cl}$} & C & 60385.57 & 344254.93 & 0.15 & $* * *$ & $\uparrow$ & $* * *$ & -1.41 & 924.82 & 0.00 & $* * *$ & $\uparrow$ & $* * *$ \\
\hline & $\mathrm{S}$ & 183594.21 & 450601.89 & 0.29 & & & & 1830.80 & 4441.00 & 0.29 & & & \\
\hline \multirow[t]{2}{*}{ FW } & $\mathrm{C}$ & 2.35 & 4.45 & 0.35 & $* * *$ & $\downarrow$ & & 9.02 & 2.02 & 0.82 & $* * *$ & $\downarrow$ & $* * *$ \\
\hline & $\mathrm{S}$ & 1.54 & 0.65 & 0.70 & & & & 2.61 & 2.02 & 0.56 & & & \\
\hline \multirow[t]{2}{*}{ SL } & $\mathrm{C}$ & 40.56 & 74.62 & 0.35 & $* * *$ & $\downarrow$ & & 182.28 & 177.35 & 0.51 & $* * *$ & $\downarrow$ & $* * *$ \\
\hline & $\mathrm{S}$ & 36.17 & 67.27 & 0.35 & & & & 136.82 & 111.39 & 0.55 & & & \\
\hline \multirow[t]{2}{*}{ SF } & $\mathrm{C}$ & 42.67 & 75.62 & 0.36 & $* * *$ & $\uparrow$ & & 204.56 & 393.03 & 0.34 & $* * *$ & $\uparrow$ & $* * *$ \\
\hline & $\mathrm{S}$ & 47.88 & 88.05 & 0.35 & & & & 401.38 & 1376.60 & 0.23 & & & \\
\hline \multirow[t]{2}{*}{$\mathrm{SH}$} & $\mathrm{C}$ & 117.45 & 697.78 & 0.14 & & & & 235.37 & 592.01 & 0.28 & $* * *$ & $\uparrow$ & $* *$ \\
\hline & $\mathrm{S}$ & 152.03 & 522.95 & 0.23 & & & & 242.81 & 1036.20 & 0.19 & & & \\
\hline \multirow[t]{2}{*}{ FS } & $\mathrm{C}$ & 0.02 & 0.04 & 0.26 & & & & 0.01 & 0.04 & 0.19 & $* * *$ & $\downarrow$ & \\
\hline & $\mathrm{S}$ & 0.02 & 0.06 & 0.23 & & & & 0.01 & 0.03 & 0.30 & & & \\
\hline \multirow[t]{2}{*}{ FH } & $\mathrm{C}$ & 54.78 & 586.27 & 0.09 & & & & 130.66 & 499.48 & 0.21 & $* * *$ & $\uparrow$ & \\
\hline & $\mathrm{S}$ & 102.72 & 460.30 & 0.18 & & & & 38.64 & 872.38 & 0.04 & & & \\
\hline \multirow[t]{2}{*}{ FR } & $\mathrm{C}$ & 3.03 & 5.97 & 0.34 & & & & 1.76 & 3.70 & 0.32 & $* * *$ & $\downarrow$ & \\
\hline & $S$ & 4.37 & 7.43 & 0.37 & & & & 1.39 & 2.30 & 0.38 & & & \\
\hline \multirow[t]{2}{*}{ NL } & $\mathrm{C}$ & 5.52 & 6.08 & 0.48 & $* * *$ & $\uparrow$ & & 2.52 & 3.94 & 0.39 & & & \\
\hline & $\mathrm{S}$ & 2.60 & 2.38 & 0.52 & & & & 2.76 & 2.30 & 0.55 & & & \\
\hline \multirow[t]{2}{*}{ FRW } & $\mathrm{C}$ & 3.15 & 37.17 & 0.08 & & & & 22.63 & 31.50 & 0.42 & $* * *$ & $\downarrow$ & \\
\hline & $\mathrm{S}$ & 11.66 & 33.89 & 0.26 & & & & 13.04 & 21.19 & 0.38 & & & \\
\hline \multirow[t]{2}{*}{ DRW } & $\mathrm{C}$ & - & - & - & - & & - & 0.46 & 1.31 & 0.26 & $* * *$ & $\downarrow$ & \\
\hline & $\mathrm{S}$ & - & - & - & & & & 0.23 & 0.38 & 0.38 & & & \\
\hline \multirow[t]{2}{*}{ F-D } & $\mathrm{C}$ & - & - & - & - & & - & 15.78 & 22.12 & 0.42 & $* * *$ & $\downarrow$ & \\
\hline & $\mathrm{S}$ & - & - & - & & & & 8.94 & 17.42 & 0.34 & & & \\
\hline \multirow[t]{2}{*}{$\mathrm{L}$} & $\mathrm{C}$ & 2.61 & 18.43 & 0.12 & $* * *$ & $\downarrow$ & $* * *$ & - & - & - & - & & - \\
\hline & $\mathrm{S}$ & 2.63 & 13.53 & 0.16 & & & & - & - & - & & & \\
\hline \multirow[t]{2}{*}{$\mathrm{a}$} & $\mathrm{C}$ & 1.42 & 6.65 & 0.18 & $* * *$ & $\uparrow$ & $* * *$ & - & - & - & - & & - \\
\hline & $\mathrm{S}$ & 2.64 & 4.82 & 0.35 & & & & - & - & - & & & \\
\hline b & $\mathrm{C}$ & 4.92 & 31.65 & 0.13 & $* * *$ & $\downarrow$ & $* * *$ & - & - & - & - & & - \\
\hline & $\mathrm{S}$ & 8.11 & 25.05 & 0.24 & & & & - & - & - & & & \\
\hline
\end{tabular}

Italics high heritabilities $(\geq 0.5)$. Significant two-way ANOVA is also indicated for treatment effects (E) and genotype by environmental interaction $(\mathrm{G} \times \mathrm{E})$. For significant treatment effect, mean tendency $(\mathrm{c} \rightarrow \mathrm{s})$ is indicated. Blanks not significant, "-" not analysed

*** Significant at $P<0.0001 * *$ Significant at $P<0.001$

More QTLs for FW have been detected than for FN. Moreover, comparing both components of fruit yield, no FN QTL co-locates with a TW QTL but with a FW QTL. A minimum of $10 \mathrm{FW}$ QTLs have been detected, four of them (at chromosomes 1, 2, 3 and 4) might be considered common between populations. In all cases, as expected, the wild allele is associated with a lower fruit weight under both conditions. Three FW QTLs in $\mathrm{P}$ and 5, in the $\mathrm{C}$ population are detected under both conditions but their contributions and genotypic means are always lower under salinity. From all FW QTL detected, only fw8.1 (in the C population) is salinityspecific.
For significantly correlated traits NL and SF, only one genomic position, containing $n l 5.2$ and sf5.1, is associated with both traits in the $C$ population. Several NL or SF QTLs (sf1.1, sf5.2, nl5.1 and nl10.1) co-locate with FN (fn1.2, fn5.2 and fn5.1) or TW QTLs (tw10.1), respectively, explaining, at least in part, the negative correlation between these two groups of traits. Unexpectedly, two NL QTLs (nl5.2 and nl12.1) co-locate with QTLs involved in $\mathrm{Cl}^{-}$leaf concentration.

Salinity drastically affects the detection of $\mathrm{Cl}$ and $\mathrm{SF}$ QTLs given that none of them were detected under both conditions. QTL $\times \mathrm{E}$ analysis by using the interval mapping procedure revealed more QTLs with significant 
Table 3 List of QTLs detected in the $\mathrm{P}$ and $\mathrm{C}$ populations, indicating: the chromosome (Chr), the marker showing the lowest $P$ value (Kruskal-Wallis or ANOVA tests) and the treatment (Tr)

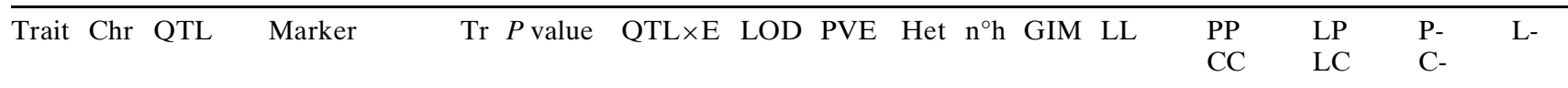

$\mathrm{P}$ population

\begin{tabular}{|c|c|c|c|c|c|c|c|c|c|c|c|c|c|c|c|c|}
\hline \multirow[t]{6}{*}{$\mathrm{Cl}$} & \multirow[t]{2}{*}{2} & $c l * 2.2$ & SSRW26_175 & $\mathrm{S}$ & 0.0021 & & - & - & & 19 & $\mathrm{~L}-$ & 2018.88 & 1723.18 & 2117.50 & & \\
\hline & & $c l 2.3$ & SSR9_220 & $\mathrm{C}$ & 0.0010 & & 2.47 & 7.7 & & 17 & LL & 1105.25 & 853.30 & 1028.88 & & \\
\hline & \multirow[t]{2}{*}{6} & $c l * 6.1$ & STC4 & $\mathrm{S}$ & 0.0049 & 0.0026 & 2.19 & 7.20 & & 14 & L- & 1993.78 & 1716.03 & 2031.90 & & \\
\hline & & cl6.2 & SSRW350_298 & $\mathrm{C}$ & 0.0022 & 0.0047 & 2.1 & 6.6 & & 11 & PP & 854.11 & 1084.80 & 965.91 & & \\
\hline & 10 & cl10.1 & SSRW223_230 & $\mathrm{C}$ & 0.0005 & 0.0187 & 2.59 & 8.1 & & 17 & LL & 1114.94 & 851.08 & 893.29 & & \\
\hline & 12 & $c l * 12.1$ & TG16_530 & $\mathrm{S}$ & 0.0057 & - & - & - & wh & 5 & $\mathrm{~L}_{-}$ & 1998.17 & 1738.68 & 2038.37 & & \\
\hline \multirow[t]{7}{*}{ FN } & 1 & fn1.2 & SSRW26_750 & $\mathrm{C}$ & 0.0001 & - & 2.64 & 8.30 & & & $\mathrm{P}-$ & 6.80 & & & 10.81 & \\
\hline & & & SSRW44_700 & $\mathrm{C}$ & 0.0001 & - & 2.75 & 8.70 & & & $\mathrm{PP}$ & & 11.42 & & & 7.11 \\
\hline & & & & $\mathrm{S}$ & 0.0002 & & 2.86 & 9.40 & & & PP & & 12.37 & & & 7.59 \\
\hline & & & SSR30_300 & $\mathrm{C}$ & 0.0001 & - & 2.67 & 8.40 & & & $\mathrm{P}-$ & 7.21 & & & 11.50 & \\
\hline & & & & $\mathrm{S}$ & 0.0003 & & 2.50 & 8.20 & & & $\mathrm{P}-$ & 7.77 & & & 12.27 & \\
\hline & 5 & fn5.1 & SSRW115_240 & $\mathrm{C}$ & 0.0044 & - & - & - & wh & 12 & PP & 7.97 & 11.15 & 8.04 & & \\
\hline & 10 & $f n * 10.1$ & SSR24_850 & $\mathrm{S}$ & 0.0052 & - & 2.09 & 7.00 & & & PP & & 11.90 & & & 8.11 \\
\hline \multirow[t]{18}{*}{ FW } & 1 & $f w 1.1$ & SSR41_200 & $\mathrm{C}$ & $<0.0001$ & - & 3.20 & 10.00 & wh & 13 & LL & 3.45 & 2.26 & 2.70 & & \\
\hline & & & & $S$ & $<0.0001$ & & 2.51 & 8.20 & wh & 13 & LL & 2.42 & 1.59 & 1.96 & & \\
\hline & & & SSRW26_750 & $\mathrm{C}$ & $<0.0001$ & - & 2.11 & 6.70 & & & LL & 3.49 & & & 2.48 & \\
\hline & & & & $\mathrm{S}$ & $<0.0001$ & & 3.82 & 12.20 & & & LL & 2.62 & & & 1.64 & \\
\hline & & & SSRW44_700 & $\mathrm{C}$ & $<0.0001$ & - & 2.01 & 6.40 & & & L- & & 2.45 & & & 3.34 \\
\hline & & & & S & $<0.0001$ & & 3.76 & 12.00 & & & $\mathrm{~L}_{-}$ & & 1.61 & & & 2.50 \\
\hline & & & SSRW75_175 & $\mathrm{C}$ & $<0.0001$ & - & 2.94 & 9.10 & wh & 12 & LL & 3.38 & 2.26 & 2.58 & & \\
\hline & & & & S & $<0.0001$ & & 3.30 & 10.60 & & 12 & LL & 2.47 & 1.56 & 1.55 & & \\
\hline & & & SSR30_300 & $\mathrm{C}$ & 0.0004 & - & - & - & & & LL & 3.23 & & & 2.48 & \\
\hline & & & & S & $<0.0001$ & & 2.80 & 9.10 & & & LL & 2.40 & & & 1.63 & \\
\hline & & & STC5 & S & $<0.0001$ & - & 2.96 & 9.60 & & 16 & LL & 2.57 & 1.67 & 1.71 & & \\
\hline & 2 & $f w 2.1$ & SSR9_220 & $\mathrm{C}$ & $<0.0001$ & - & 4.56 & 15.10 & & 17 & LL & 3.62 & 2.28 & 2.96 & & \\
\hline & & & SSR12_140 & $\mathrm{C}$ & $<0.0001$ & - & 4.56 & 15.10 & & 8 & LL & 3.63 & 2.26 & 3.18 & & \\
\hline & & & & $\mathrm{S}$ & 0.0002 & & 2.22 & 7.80 & & 8 & LL & 2.46 & 1.69 & 1.97 & & \\
\hline & 3 & $f w 3.1$ & SSRW223_508 & $\mathrm{C}$ & 0.0014 & - & 2.00 & 6.30 & & 8 & LL & 3.28 & 2.34 & 2.86 & & \\
\hline & 4 & $f w 4.1$ & SSR31_130 & $\mathrm{C}$ & 0.0023 & - & - & - & wh & 11 & LL & 3.45 & 2.50 & 2.67 & & \\
\hline & 7 & $f w 7.1$ & SSR16_396 & $\mathrm{C}$ & 0.0068 & - & - & - & & & $\mathrm{L}-$ & & 2.59 & & & 3.06 \\
\hline & & & SSR24_750 & S & 0.0019 & - & - & - & & & $\mathrm{L}_{-}$ & & 1.84 & & & 2.12 \\
\hline \multirow[t]{3}{*}{ SF } & 1 & $s f^{*} 1.1$ & SSR30_300 & S & $<0.0001$ & - & 4.76 & 14.90 & & & LL & 59.27 & & & 55.01 & \\
\hline & & & SSRW44_700 & $S$ & $<0.0001$ & 0.0247 & 4.54 & 14.50 & & & $\mathrm{~L}_{-}$ & & 55.14 & & & 59.22 \\
\hline & 5 & $s f 5.1$ & S_440 & $\mathrm{C}$ & 0.0033 & - & - & - & & & LL & 55.15 & & & 52.36 & \\
\hline \multirow[t]{7}{*}{ NL } & 1 & $n l^{*} 1.1$ & SSR13_600 & S & 0.0064 & - & - & - & wh & 7 & $\mathrm{PP}$ & 11.71 & 12.63 & 11.83 & & \\
\hline & 3 & $n l 3.1$ & LEFA_550 & $\mathrm{C}$ & 0.0065 & - & - & - & wh & 7 & LL & 12.14 & 11.31 & 12.48 & & \\
\hline & 5 & $n l 5.1$ & SSRW115_240 & $\mathrm{C}$ & 0.0004 & - & - & - & & 12 & LL & 12.44 & 11.35 & 11.39 & & \\
\hline & 10 & $\underline{n l 10.1}$ & SSRW248_270 & $\mathrm{S}$ & 0.0021 & - & - & - & & 10 & LL & 12.84 & 11.80 & 11.61 & & \\
\hline & & & SSRW318_298 & $\mathrm{C}$ & 0.0001 & - & - & - & & 10 & LL & 12.59 & 11.38 & 11.47 & & \\
\hline & 12 & nl12.1 & TG69_950 & $\mathrm{C}$ & 0.0016 & - & - & - & wh & 9 & PP & 11.27 & 12.27 & 11.93 & & \\
\hline & & & TG16_530 & S & 0.0009 & - & 2.76 & 8.90 & & 5 & PP & 11.6 & 12.65 & 13 & & \\
\hline \multirow[t]{6}{*}{ TW } & 2 & $t w 2.1$ & SSR12_140 & S & 0.0003 & - & 2.96 & 9.60 & & 8 & LL & 24.79 & 14.15 & 21.23 & & \\
\hline & & & SSR9_220 & $\mathrm{C}$ & 0.0054 & - & 2.30 & 12.10 & & 17 & LL & 28.07 & 20.54 & 22.71 & & \\
\hline & 7 & $t w 7.1$ & SSR16_396 & $\mathrm{C}$ & 0.0011 & - & 3.40 & 41.30 & & & $\mathrm{~L}_{-}$ & & 18.58 & & & 27.81 \\
\hline & 8 & $t w * 8.1$ & SSRW92_500 & S & 0.0012 & - & 2.23 & 7.40 & & & LL & 22.70 & & & 13.80 & \\
\hline & 10 & $\underline{t w 10.1}$ & TG16_1000 & $\mathrm{S}$ & 0.0043 & - & 1.75 & 5.80 & wh & 9 & PP & 14.35 & 22.33 & 18.29 & & \\
\hline & & & SSRW318_298 & $\mathrm{C}$ & 0.0027 & - & 3.30 & 10.20 & & 10 & $\mathrm{P}-$ & 16.58 & 26.45 & 35.42 & & \\
\hline \multicolumn{17}{|c|}{ C population } \\
\hline \multirow[t]{3}{*}{$\mathrm{Cl}$} & 2 & $c l * 2.1$ & SSRW66_200 & S & 0.0051 & 0.0140 & 2.01 & 11.00 & $\mathrm{~h}$ & 14 & $\mathrm{~L}_{-}$ & 167.11 & 158.30 & 214.44 & & \\
\hline & 5 & $c l * 5.1$ & SSRW344_430 & $\mathrm{S}$ & 0.0009 & 0.0006 & - & - & & 8 & $\mathrm{C}-$ & 150.89 & 188.54 & 193.88 & & \\
\hline & 8 & $c l^{*} 8.1$ & TG15_900 & $\mathrm{S}$ & 0.0003 & 0.0008 & 3.44 & 13.60 & & & $\mathrm{C}-$ & 154.73 & & & 196.99 & \\
\hline \multirow[t]{6}{*}{ FN } & 1 & fn1.1 & SSR12_750 & $\mathrm{C}$ & 0.0023 & - & - & - & & 10 & $\mathrm{C}-$ & 7.09 & 9.52 & 10.65 & & \\
\hline & & fn1.2 & TG16_440 & $\mathrm{C}$ & 0.0034 & - & 2.17 & 8.70 & wh & 7 & $\mathrm{CC}$ & 6.41 & 10.12 & 7.31 & & \\
\hline & & & & $\mathrm{S}$ & 0.0008 & & 2.03 & 9.20 & & 7 & $\mathrm{CC}$ & 3.66 & 5.67 & 4.86 & & \\
\hline & 5 & fn5.2 & C_1018 & $\mathrm{C}$ & 0.0022 & - & 2.38 & 9.70 & & 13 & $\mathrm{CC}$ & 6.44 & 10.57 & 8.00 & & \\
\hline & & & & $\mathrm{S}$ & 0.0009 & & 2.83 & 13.70 & wh & 13 & $\mathrm{CC}$ & 3.47 & 6.16 & 5.17 & & \\
\hline & 6 & fn6.1 & CT206_290 & $\mathrm{C}$ & 0.0038 & - & - & - & & 9 & $\mathrm{C}_{-}$ & 5.63 & 9.46 & 9.52 & & \\
\hline
\end{tabular}


Table 3 continued

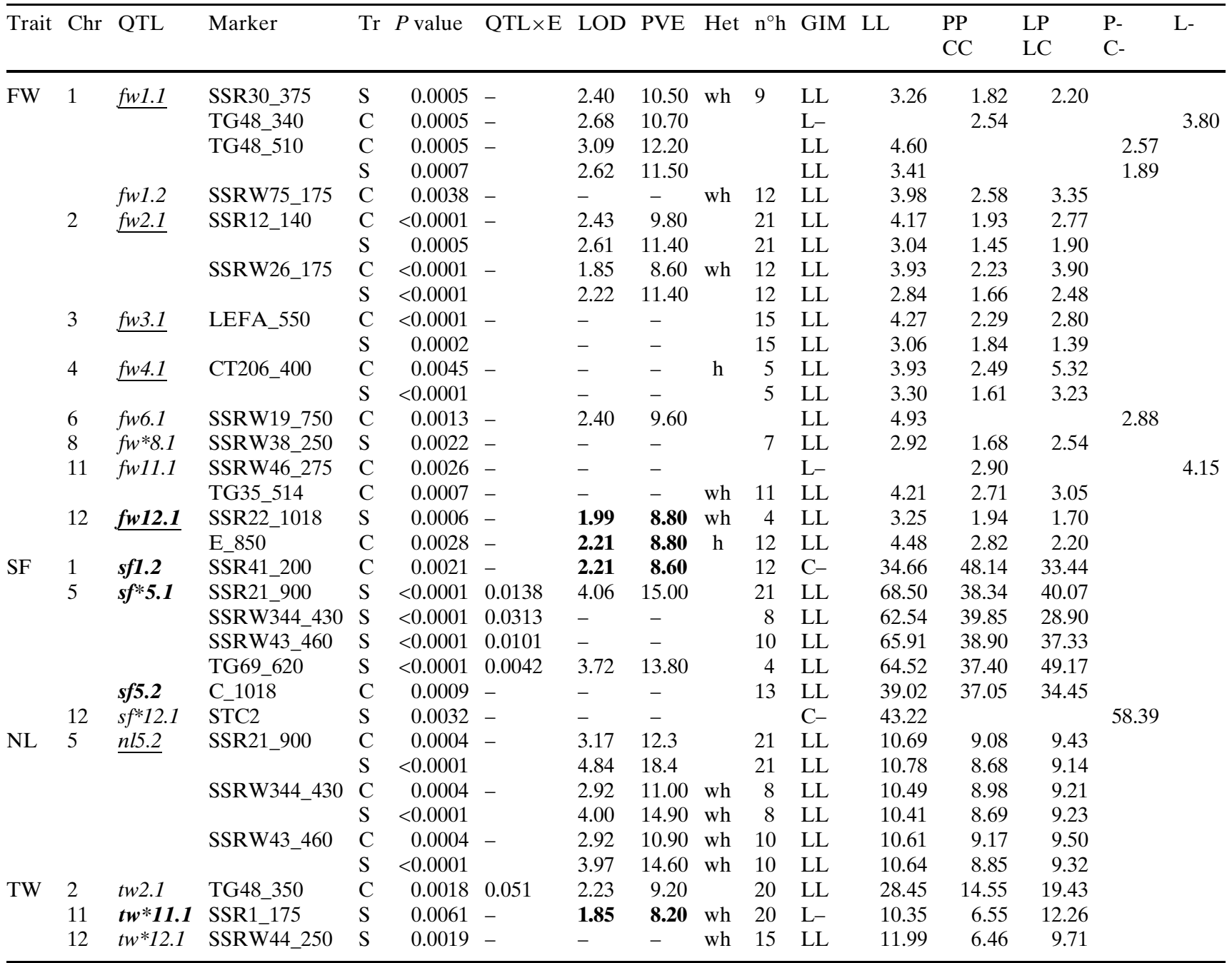

Significant $P$ values from QTL $\times$ E analysis by ANOVA are also included. In some cases (specified at the "Het" column), the detection depends on ignoring (wh) or considering $(\mathrm{h})$ the heterozygote class. The number of heterozygotes per marker $\left(\mathrm{n}^{\circ} \mathrm{h}\right)$ is specified. Results from interval mapping are also included: LOD value and percentage of variance explained (PVE). An asterisk at the QTL name means significant only under saline treatment. Underlined QTLs are those significant under both treatments. $L L$ phenotypic mean of lines homozygous for the $S$. lycopersicum alleles, $P P$ phenotypic mean of lines homozygous for the $S$. pimpinellifolium alleles, $C C$ phenotypic mean of lines homozygous for the $S$. cheesmaniae alleles, $L P$ and $L C$ phenotypic mean of heterozygote lines from $\mathrm{P}$ and $\mathrm{C}$ populations, respectively. $L-$ phenotypic mean of lines with $L$ being dominant, $P$ - and $C$ - phenotypic mean of lines when the wild allele is dominant in the $\mathrm{P}$ and $\mathrm{C}$ populations, respectively. Genotype increasing the mean of the trait (GIM) is specified depending on the dominance or codominance nature of the marker. QTLs displaying heterotic effects are represented in bold. Bold face IM values represent LOD values when dominance is allowed when using interval mapping methodology. "-" not significant

interaction than by ANOVA. In addition to those detected by ANOVA (some $\mathrm{Cl}$ and SF QTLs in Table 3), SSR41_200 (fw1.1), SSR9_200 (fw2.1), SSRW223_508 (fw3.1), SSR30_300 (sf1.1) and SSR16_396 $(t w 7.1)$ at the $\mathrm{P}$ population, and SSRW19_750 ( fw6.1) at the C population showed significant QTL $\times$ E effects by interval mapping.

A candidate gene for flowering time, Falsiflora (LEFA_550), was found to be significantly associated with NL in the $P$ while in the $C$ population it is significantly associated with FW. The other candidate for flowering time (PhyB2) has not been found significantly associated with SF or NL variation in the populations. On the other hand, the marker associated with $s f 5.2$ in the C population, C_1018, is highly similar ( $E$ value: $2 \times 10^{-27}$, from 581 to $756 \mathrm{bp}$ ) to the gene coding for the No Apical Meristem-like (NAM) protein 9 in Petunia (AF509872.1). Concerning their genomic position, PhyB2 and C_1018 do not join to the group P5a (as in the case of the $\mathrm{C}$ population) but to $\mathrm{P} 4 \mathrm{~b}$ at LOD 3.0.

In the $\mathrm{P}$ population, homozygous lines for the allele of the cultivated species ( $L L$ genotype) are always 


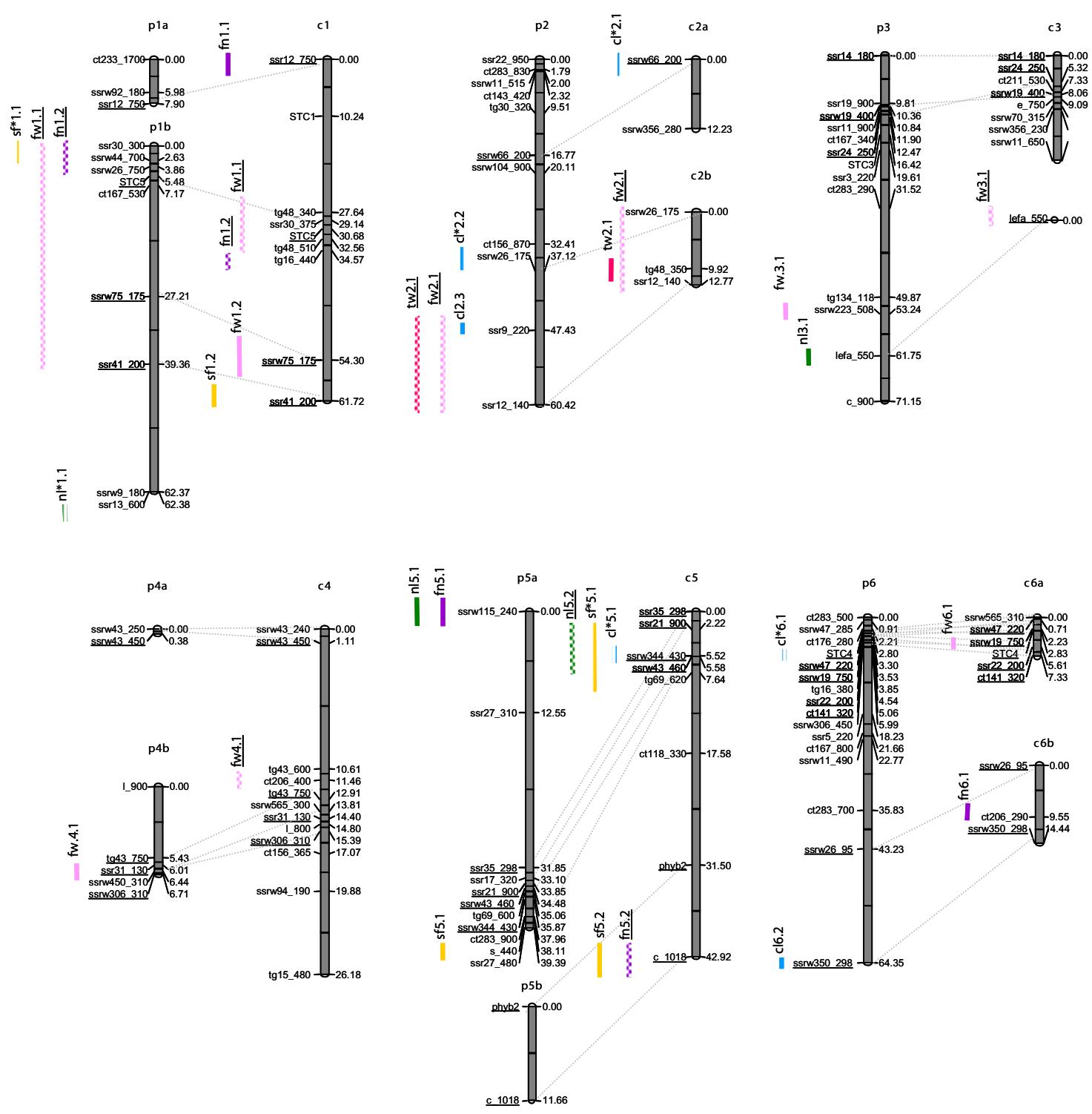

Fig. 2 Linkage maps obtained for the $\mathrm{P}$ and the $\mathrm{C}$ populations. Common markers are connected by lines. Bars, with the name of the QTL, are indicating markers that show significant association $(P<0.01)$ with the phenotypic variation of FW, TW, FN, SF, NL

associated with late flowering while in the $\mathrm{C}$ population, the allele delaying flowering depends on the QTL. Thus, $L L$ genotype at both, sf5.1 and $s f 5.2$, is associated with late flowering while $C$ allele at $s f 1.2$ and sf12.1 delays flowering.

\section{Discussion}

Salinity effects and salt tolerance

Tomato yield reduction is economically the most important trait affected by salt stress. At relatively low and $\mathrm{Cl}$. Depending on the salinity condition under which the QTL is detected, the bar is continuous (control), discontinuous (salinity) or waved (both conditions)

electric conductivities, the main reduction in yield involves FW whilst at higher electric conductivities it is better explained by FN reduction (Van Ieperen 1996; Cuartero and Soria 1997). In our study, high salinity has caused a reduction of fruit yield, decreasing FW and, in the case of the $\mathrm{C}$ population, also FN (Table 2). Similarly to results for $F_{2}$ (Monforte et al. 1997b), the P population has salt tolerance genes related to $\mathrm{FN}$, but not to $\mathrm{FW}$ because $\mathrm{G} \times \mathrm{E}$ interaction is not significant for $\mathrm{FW}$; i.e. $\mathrm{FW}$ reduction equally affects to all lines or genotypes. In the $\mathrm{C}$ population, significant $\mathrm{G} \times \mathrm{E}$ interaction for both FN and FW indicates that the amount of the reduction for both traits varies among geno- 

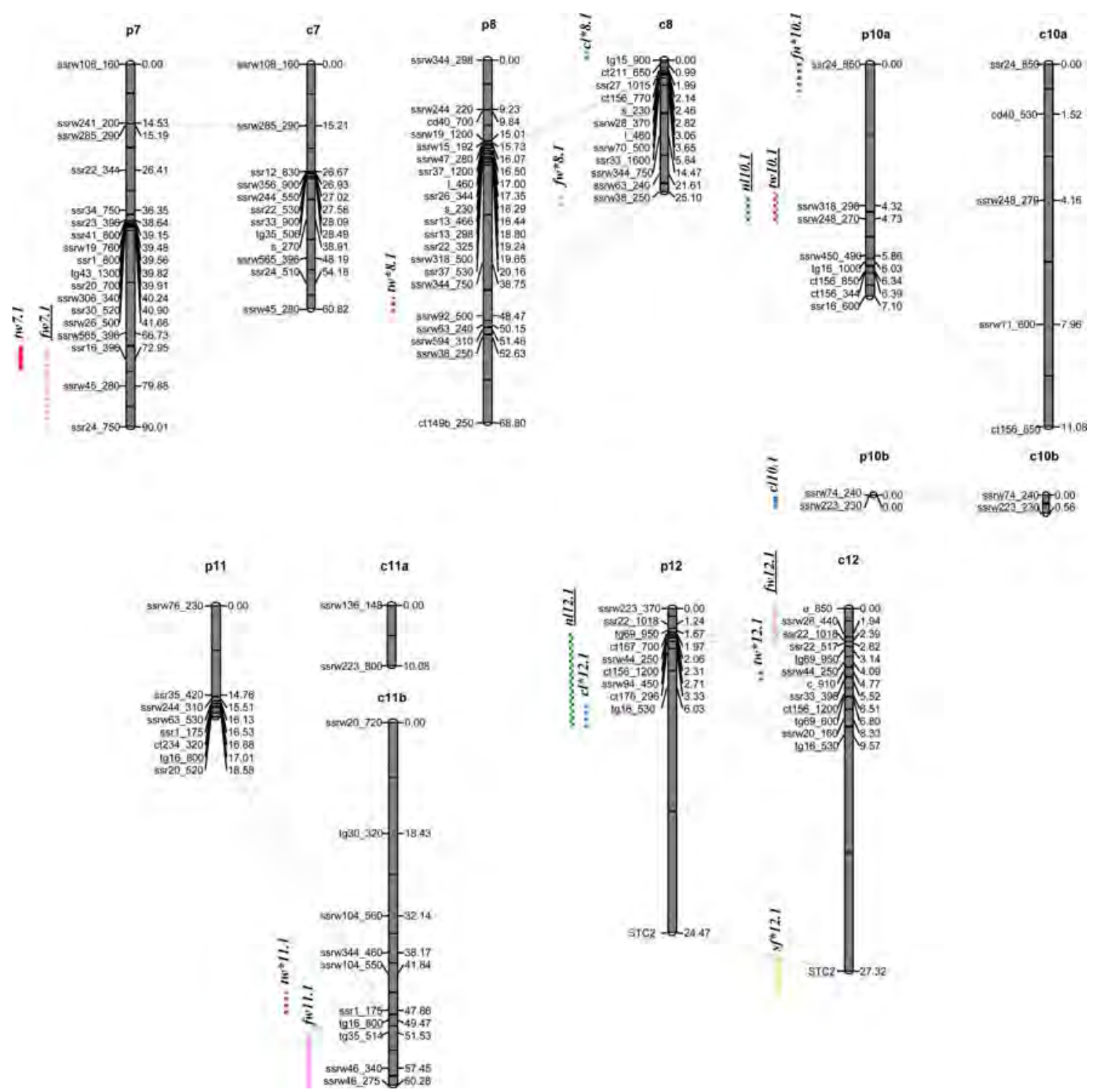

Fig. 2 continued

types. Lesser reductions under saline treatment in some lines is the salt tolerance effect we want to find out. Which are the physiological and biochemical processes involved? A better understanding of the whole plant behaviour under changing salinity levels is needed to improve salt tolerance efficiently. This knowledge should involve not only the trait defined as salt tolerance but also other correlated traits because correlated responses may constrain the success of breeding programmes. All evaluated traits are significantly affected by salinity, at least in one of the populations (Table 2). When the trait is affected in both populations, the direction of the change is the same. Salinity is accompanied by a reduction of the stem diameter and length, the number of flowers per truss, the fruit yield, and by a delay in flowering.
The study of the relationships among traits might also unveil early salt tolerance indicators. Since the results of the PCA match results of correlations, this discussion will be focused just on correlation results. In both populations, stem length (SL) under saline treatment might be used for early selection since its evaluation (6 weeks after germination) is significantly correlated with TW, mostly through its correlation with FN under salinity (Table 1). Foolad (1996) and Bolarín et al. (1991) also suggested the use of SL for directional selection to improve salt tolerance. Nevertheless, although significant, the correlation coefficients are low. Broad sense heritability estimates of SL are also low. These two features significantly limit the reliability of SL, as an alternative to fruit yield, as selection criterion for salt tolerance in tomato. 
Verslues et al. (2006) have pointed out that the effects of salt can be quantified through effects on growth, such as root fresh or dry weight. Thus, they report an important difference on Arabidopsis root growth when osmotic and salt stresses are compared; i.e. seedlings grown in agar plates with $100 \mathrm{mM} \mathrm{NaCl}$ had a greater inhibition of root growth, most likely caused by direct toxicity of $\mathrm{Na}^{+}$. We have found a significant reduction of fresh root weight under salinity only in the $\mathrm{C}$ population (Table 2). No significant correlation has been found between FRW and any yield component in the present study.

\section{QTL analysis}

\section{Leaf chloride concentration}

Many important crops are susceptible to $\mathrm{Cl}^{-}$toxicity during cultivation. This is a major constraint to horticultural production on irrigated or saline soils (Mass and Hoffman 1977; Xu et al. 2000). Differences between cultivars to withstand $\mathrm{Cl}^{-}$toxicity are frequently related to the ability to restrict $\mathrm{Cl}^{-}$transport into the shoot; as a result, $\mathrm{Cl}^{-}$accumulation has been suggested as a suitable trait for screening plant salt tolerance in germplasm collections (Storey and Walker 1999; Munns et al. 2002). No significant correlation between $\mathrm{Cl}$ and tomato fruit yield has been found, questioning the value of this trait as a salt tolerance indicator in tomato. In spite of this lack of correlation, Cl QTLs have been also investigated trying to integrate the fruit yield components and the physiological behaviour of the whole plant. Thus, $c l 2.3$ has been found associated with the same marker as fw2.1 and tw2.1 at $\mathrm{P}$ population under control condition suggesting a possible role in the plant nutrition.

Plants have been classically classified into two groups depending on their response to salts. The main strategy for glycophytes is to control ion flux into root xylem, restricting ion movement to the shoot (for review, see Hasegawa et al. 2000). In contrast, the halophytic response (Greenway et al. 1980) is based on three adaptation strategies, compartmentation of toxic ions, accumulation of osmolytes, and conservation of water (Bohnert 1995). Gene effects at QTLs responsible for variation in young leaves $\mathrm{Cl}^{-}$concentration agree with previous physiological studies establishing the nature of salt response within tomato species. The cultivated tomato and the closely related wild species S. pimpinellifolium have been shown to display a glycophitic response to salinity based on salt exclusion from young leaves (Cuartero et al. 1992; Bolarín et al. 1991; Pérez-Alfocea et al. 1993; Foolad 1997; Santa Cruz et al.1998). S. pimpinellifolium alleles at Cl QTLs are associated with a low leaf $\mathrm{Cl}^{-}$concentration. In contrast, $S$. cheesmaniae has been shown to display a halophytic response based on the inclusion of $\mathrm{Cl}^{-}$into the vacuole (Sacher et al. 1983; Tal and Shanon 1983; Bolarín et al. 1991; Pérez-Alfocea et al. 1994). In the C population, two out of the three QTLs detected (cl5.1 and cl8.1) fit this halophytic habit since higher concentrations of $\mathrm{Cl}^{-}$in young leaves were found in $C C$ versus $L L$ lines.

Even though no significant correlation between $\mathrm{Cl}$ and NL has been found, $c 15.1$ and cl12.1 locate in the same genomic region as $n l 5.2$ and $n l 12.1$ in the $\mathrm{C}$ and $\mathrm{P}$ populations, respectively. The wild allele is associated with less $\left[\mathrm{Cl}^{-}\right]$and fewer leaves until flowering in $\mathrm{P}$, while in the $C$ population this association is negative. These gene effects do not explain the fact that salinity is accompanied by a flowering delay in both populations. Therefore, other hypothetic causes, such as a salinity induced increment of sugars in the phloem, might better explain the flowering delay (Ohto et al. 2001).

\section{Flowering related traits}

Flowering time is one of the most outstanding factors conditioning fruit harvesting time, and is measured generally by the number of days between sowing and anthesis or the number of nodes until the first flower. Flowering earliness has been related to low fruit number (Monforte et al. 1999) and fruit weight reduction (Grandillo et al. 1999), presumably because plants do not have enough time and biomass to produce and keep a full load of high-quality fruits (Khalf-Allah and Peirce 1963). Thus, the consideration of these traits for yield improvement becomes relevant. No correlation between FW versus SF or NL has been detected in the present study, indicating the possibility to improve both traits together. QTLs for both traits co-locate only in chromosome $\mathrm{P} 1$, where $L$ alleles delay flowering under salinity and increases FW. Nevertheless, $C$ alleles at both $s f 1.2$ and fw1.1, loosely linked in chromosome $\mathrm{C} 1$, delay flowering (under control conditions) and reduces fruit weight, respectively. Therefore, selection for the $L$ allele at this region, in the $\mathrm{C}$ population, would presumably allow to obtain earlier, larger fruits, in absence of salinity.

Unlike the results of Monforte et al. (1999) using the $\mathrm{C}$ population at $\mathrm{F}_{2}$, a negative correlation has been detected between flowering time versus FN and TW. In addition to the difference in the inbreeding generation, the day length conditions during both experiments were also different. The characterization of the $\mathrm{F}_{2} \mathrm{C}$ 
population was carried out in long day conditions, then, S. cheesmaniae (considered a short day plant) flowered 20 weeks later than the cultivated species. Therefore, comparisons between both studies (at $\mathrm{F}_{2}$ and $\mathrm{F}_{7}$ of the $\mathrm{C}$ population) on flowering time should be taken with caution. In agreement with results of correlation analysis, the distribution of QTLs for SF (or NL) and FN (or TW) is certainly coincident in some genomic regions for $\mathrm{P}(f n 1.2, f n 5.1$ and $t w 10.1)$ and for C (fn5.2). In all cases $L$ allele delays flowering and decrease the number of fruits. There is only one SF QTL (sf12.1 in C, under salinity) where $L$ does not delay flowering.

SF and NL are positively correlated traits, especially in the $\mathrm{P}$ population, but the only putative pleiotropic QTL is detected in the C population, where $s f 5.1$ and nl5.2 co-locate and show large percentages of variance explained (PVEs). Overlapping SF and NL QTLs have been previously detected on chromosome 5 (at Phytochrome $B 2$ ) in a $\mathrm{F}_{2}$ population derived from the cross between S. lycopersicum and S. chmielewskii (JimenezDiaz, Lozano and Martinez-Zapater, personal communication) where the S. lycopersicum allele is associated with early flowering. De Vicente and Tanksley (1993) have also reported a QTL for flowering time in chromosome 5 in a cross between $S$. lycopersicum and $S$. pennelli.

Concerning flowering time candidate gene analysis, present results from QTL analysis support two of them, Falsiflora and No Apical Meristem. Falsiflora, the tomato orthologue of Floricaula and Leafy, has been shown to control flowering time and floral meristem identity (Molinero-Rosales et al. 1999). Concerning No Apical Meristem, Sablowski et al. (1998) have reported that a homologue is an intermediate target of the floral homeotic genes Apetalla3/Pistillata. In Arabidopsis, AtNAM encodes a transcription factor whose expression is restricted primarily to the region of the embryo including the SAM (Duval et al. 2002). Therefore, taking into account their position, their associated phenotypic variation, and the above functional information from molecular genetic studies, Falsiflora (here as the LEFA_550 marker) and a homologue of No Apical Meristem (the C_1018 marker) seem plausible candidates for $n l 3.1$ and $s f 5.2$, respectively.

After leaf chloride concentration, SF is the trait most affected by salinity given that all QTLs detected under control are different from those under salinity. Since the PVEs of its QTLs under salinity are among the highest found in this study, the differential location does not seem due to random errors. In fact, QTL $\times \mathrm{E}$ interaction is significant only at some $\mathrm{Cl}$ and SF QTLs (Table 3). Therefore, concerning the relevant genes involved, the genetic control of a trait may change in absence of significant $\mathrm{G} \times \mathrm{E}$ interaction (The P population in Table 2), supporting the complementary nature of the information provided by the QTL analysis. Similar results have been found by Malmberg et al (2005) for fitness-related traits using Arabidopsis RILs because although the total number of significant additive and epistatic QTLs was similar under the two growth conditions (field and greenhouse), the map locations were largely different. On the other hand, Juenger et al (2005) have reported that, as a whole, QTL-treatment interaction terms explained just around $19 \%$ of the total variation for flowering time in a RIL population of Arabidopsis. These authors also point out that in three out six cases exhibiting this interaction corresponded to allelic sensitivity. If salinity reduces allelic differences at a QTL then it becomes undetected. This might be the case of $n l 3.1$ (located at LEFA_550) in the P population.

\section{Yield related traits: breeding for salt tolerance}

Salinity effects on tomato fruit yield have received little attention through analysis of QTL. Total fruit weight is a complex trait whose main components are FW and FN. The contribution of FW is clearly larger than that of FN, since most of the TW QTLs co-locate with FW QTLs. However some exceptions occur in the P population for $t w 10.1$ (near the salt-specific QTL fn10.1) and for the salt-specific $t w 8.1$. Concerning utilization of wild genetic resources, from all TW QTLs, wild allele is advantageous only at $t w 10.1$.

QTLs involved in fruit weight variation have been extensively studied in different segregating populations and advanced crosses (Grandillo et al. 1999; SalibaColombani et al. 2001; Lecomte et al. 2004; Tanksley 2004; Paterson et al.1990; Goldman et al.1995; Grandillo and Tanksley 1996; Doganlar et al. 2002; van der Knaap and Tanksley 2001). QTLs in chromosomes 4 and 12 have only been detected previously by Goldman et al. (1995). The comparative analysis of these QTL studies by Grandillo et al. (1999) concluded that at least 28 conserved QTLs are the responsible for FW variation in tomato. The number of FW QTLs detected per study ranges from 3 to 18 and the percentage of variance explained by QTLs depends largely on the population, experimental design and statistical thresholds. Six out of the 28 FW QTLs, on chromosomes 1, 2, 3, 4 and 9, are considered major QTLs since their individual contribution in at least one of the experiments was more than $20 \%$ of total variance. In our study, chromosomes 1, 2, 3 and 4 contain FW QTLs that have been detected in both populations without salinity. 
None in chromosome 9. The percentages of variance explained (PVEs), $15.1 \%$ at most, are lower than those reported in previous studies.

The simple fact that some FW QTL ( $f w 3.1$ and $f w 4.1$ in P population and $f w 1.2, f w 6.1$ and $f w 11.1$ in C population) are only detected under non-saline condition (salt-sensitive FW QTLs) might explain genetically the fruit weight reduction under salt stress in these populations. The only QTL for FW detected only under salt treatment is $f w 8.1$ (in the $\mathrm{C}$ population). Since the allele increasing this trait $(L)$, comes from the salt sensitive parent (unable to yield fruits under this salinity level), other gene(s) from the wild parent (or lack of genes from the cultivated one) must be necessary, suggesting the involvement of epistatic interactions.

Concerning fruit number, wild species have more flowers per truss and consequently more fruits per truss than the cultivated tomato. Wild alleles at FN QTLs always increase the trait. The most significant QTL for FN is fn1.2 (P population). Co-location of QTLs for the number of flowers per truss and fruits per truss (data no shown) in chromosome P1 relates $f n 1.2$ with the flowering pattern. Doganlar et al. (2002), using S. pimpinellifolium also, found a QTL for the number of flowers per truss in chromosome 1 . The coincidence of map position between $f n 1.2$ and a FW QTL where the effect of the wild allele diminishes FW limits its use for breeding purposes, the same problem is observed for $f n 1.2$ in the $\mathrm{C}$ population.

QTLs for fruit number in chromosome 5 were detected in both populations, and none of them were associated with a significant fruit weight reduction offering the opportunity to be used in breeding, especially $f n 5.2$ of $\mathrm{C}$ population because of its relatively large PVE under salinity $(13.7 \%)$. The wild allele is associated with more fruits and an earlier yield. Another important QTL to improve salt tolerance is fn10.1, detected in $\mathrm{P}$ population, because it is the only FN QTL detected only under salt stress. This locus is not linked with any undesirable feature and overlaps with $t w 10.1$, where $P P$ genotype is associated with a higher fruit yield under both conditions.

Also in P population, $t w 8.1$ is a salt specific QTL. It co-locates with the only QTL detected for fruit set percentage under saline conditions (data not shown) indicating the possible presence of genes affecting fruit set success under stress conditions resulting in TW variation. At this locus the increase of FS and TW under saline conditions were both related to $L L$ genotype, contrasting with the fact that $S$. lycopersicum parent fails to yield fruits under salt treatment used. Therefore, again the salt tolerance effect of this $L$ gene must be masked within the genome of the parent line, and it is only displayed under salinity when other(s) genes of S. lycopersicum are absent, or other(s) from the S. pimpinellifolium are present. Given that the associated markers with $t w 8.1$ (in P) and $f w 8.1$ (in C) are closely linked $(3 \mathrm{cM})$, and the beneficial allele under salinity comes from the salt sensitive parent in both populations, the first hypothesis (absence of other epistatic $S$. lycopersicum gene(s)) is the simplest one to explain the salt tolerance effect of the $L$ allele at this genomic region.

\section{QTL analysis of RILs under trial}

QTL analysis using a population of RILs presents several advantages over a $F_{2}$ concerning its accurateness such as a more reliable assignment genotype-phenotype and more power to detect additive QTL. Additionally, the RIL design allows a better estimation of trait heritability and the evaluation of as many traits as desired under different environmental conditions, allowing an integrative approach of agronomic and physiological traits that makes biological interpretation of QTL analysis easier.

In previous papers on fruit traits in tomato, their heritabilities were not reported or were estimated only through control plants, generally the parents (Asins et al. 1993; Saliba-Colombani et al. 2001). Since the non-genetic component might differ from one genotype to another a methodology which takes into account both components of variation within the whole population has been considered here. Thus, the methodology used allows a comparison of variance components between treatments and populations. As expected, a reduction in the genetic component under salinity is, sometimes, accompanied by the lack of detection of control-detected-QTLs, such as in the case of FW, suggesting that the allelic (and beneficial) differences under control, decrease or even disappear under salinity. A certain amount of $\mathrm{G} \times \mathrm{E}$ interaction might be explained following this reasoning when comparing control versus salinity-detected QTLs. Additionally, heritability estimates are useful also to check (and understand) the lack of QTL detection, such as for $\mathrm{Cl}$ under control condition at the $\mathrm{C}$ population, which is indicative of a certain control over the detection of false QTLs at the chosen significance level.

A limitation of the RIL design is that linkage disequilibrium affects much shorter genomic regions than other segregating populations based on fewer recombination cycles. Therefore, for a similar marker density, fewer QTLs are expected to be detected in the RIL population (although precision might be gained). 
A major drawback of RIL (and DHL) design appears when the gene action deviates from additivity towards overdominance, then QTLs with an overdominant gene action become undetected in completely homozygous lines such as in DHL populations. A certain degree of heterozygosity at $\mathrm{F}_{7}$ generation has been found, mainly at the $\mathrm{C}$ population (Villalta et al. 2005). It has allowed the detection of heterotic effects but it also has complicated the QTL analysis because results on QTL detection change if heterozygous class is considered or not (h and wh cases in Table 3 ). We could ignore the heterozygote class but it implies a loss of information. In fact, genotypic means clearly suggest heterotic effects at certain genomic positions (bold QTLs in Table 3) for some traits such as $\mathrm{Cl}$ and plant vigour related traits, in general. However, a major problem arises when interval mapping methodology is used allowing dominance because new QTLs appear that are not significant under strict additivity or using methodologies based on one marker at a time. We have reported here some QTLs detected by interval mapping allowing dominance (shaded LOD in Table 3) but only cases where the heterozygote shows heterosis and they are supported by ANOVA or Kruskal-Wallis tests. PVEs estimated in some of these cases are suspiciously high ( $t w 7.1$ in $\mathrm{P}$ and $f n 1.1$ in C).

In addition to the unusual level of heterozygosis and the deviation from the completely additive QTL model, the distribution of most traits deviate from normality limiting the suitability of the methodologies generally used for QTL detection. Other remarkable difference when comparing $\mathrm{F}_{2}$ and $\mathrm{F}_{7}$ generations, concerns $\mathrm{G} \times \mathrm{E}$ interaction in $\mathrm{P}$ population for $\mathrm{FW}$ (significant in $\mathrm{F}_{2}$ ) and $\mathrm{FN}$ (non-significant in $\mathrm{F}_{2}$ ). These observations suggest that cumulative recombination along the inbreed generations changes, at least, some genetic parameters of quantitative traits. It is well known (Falconer 1960) that the reduction of heterozygosis with inbreeding causes a redistribution of genetic variance in terms of genetic differentiation between lines and genetic uniformity within lines. Thus, when inbreeding is complete and the interaction of genetic variance arising from epistasis is neglected, the genetic variance in the population as a whole is doubled, and all of it appears as the between line component. Therefore, if QTLs detected at $\mathrm{F}_{2}$ correspond to single genes (and not to blocks of genes), we should expect higher PVEs in $F_{7}$ than in $F_{2}$. Since what we have observed is that estimated PVEs at $F_{7}$ are the lowest, at least one of the assumptions (single genes instead of blocks of genes, and lack of epistasis) must fail. How often a QTL represent a block of genes? In studies with model organisms (Cohen et al. 2000; Blumenthal et al. 2002;
Lercher et al. 2002) functionally interacting genes are often closely located and tightly linked on a chromosome. In tomato, Monforte et al. (2001) and Chen and Tanksley (2004) have reported QTLs likely to be composed of mùltiple linked genes. But, on the other hand, several single genes have already been identified as responsible of QTLs (Korstanje and Paigen 2002; Morgante and Salamini 2003; Paran and Zamir 2003). Therefore, both kinds of QTLs seem to exist in tomato. The involvement of epistasis will be approached in a future study.

In conclusion, this first comparative study of two populations of RILs that share the female progenitor has shown remarkable differences in the QTL location of the target traits, under both control and salinity conditions. The magnitude and direction of the allelic difference at each QTL depends on the wild allele (which is not always possible to predict between wild species), the level of salinity and the genetic background. Given the low contribution of the fruit yield QTLs found and the involvement of the genetic background, other strategies to improve adaptation to high salinity are being investigated.

Acknowledgments This work was supported in part by grants from IVIA (IV), and INIA (RTA01-113-C2 and RTA04-075-C2). Authors thank Drs. Jimenez-Diaz and Martinez-Zapater for the information on the flowering time gene candidates, and I. Pereira, J. Pérez-Panadés, P. Cirujeda and J. Puchades for technical assistance.

\section{References}

Al-Doss AA, Smith SE (1998) Registration of AZ-97MEC and AZ-97MEC-ST very nondormant alfalfa germplasm pools with increased shoot weight and differential response to saline irrigation. Crop Sci 38:568-568

Asins MJ, Breto MP, Carbonell EA (1993) Salt tolerance in Lycopersicon species. 2. Genetic-effects and a search for associated traits. Theor Appl Genet 86:769-774

Ausín I, Alonso-Blanco C, Martinez-Zapater JM (2005) Environmental regulation of flowering. Int J Dev Biol 49:689-705

Basten CJ, Weir BS, Zeng Z-B (2002) QTL Cartographer, Version 1.17. Department of Statistics, North Carolina State University, Raleigh, USA

Blumenthal T, Evans D, Link CD, Guffanti A, Lawson D, Thierry-Mieg J, Thierry-Mieg D, Chiu WL, Duke K, Kiraly M, Kim SK (2002) A global analysis of Caenorhabditis elegans operons. Nature 417:851-854

Bohnert HJ (1995) Coping with water-deficit, application of biochemical principles. Plant Phys 108:5

Bolarín MC, Fernandez FG, Cruz V, Cuartero J (1991) Salinity tolerance in 4 wild tomato species using vegetative yield salinity response curves. J Am Soc Hortic Sci 116:286-290

Chen KY, Tanksley SD (2004) High resolution mapping and functional analysis of se2.1: a major stigma exsertion quantitative trait locus associated with the evolution from allogamy to autogamy in the genus Lycopersicon. Genetics 168:1563-1573 
Cohen BA, Mitra RD, Hughes JD, Church GM (2000) A computational analysis of whole-genome expression data reveals chromosomal domains of gene expression. Nat Genet 26:183-186

Cuartero J, Soria T (1997) Productividad de tomates cultivados en condiciones salinas. Actas de horticultura 16:214-221

Cuartero J, Yeo AR, Flowers TJ (1992) Selection of donors for salt-tolerance in tomato using physiological traits. New Phytol 121:63-69

Cuartero J, Bolarín MC, Asins MJ, Moreno V (2006) Increasing salt tolerance in the tomato. J Exp Bot 57:1045-1058

De Vicente MC, Tanksley SD (1993) Analysis of transgressive segregation in an interspecific tomato cross. Genetics 134:585-596

Dierig DA, Shannon MC, Grieve CM (2001) Registration of WCL-SL1 salt tolerant Lesquerella fendleri germplasm. Crop Sci 41:604-605

Doganlar S, Frary A, Ku HM, Tanksley SD (2002) Mapping quantitative trait loci in inbred backcross lines of Lycopersicon pimpinellifolium (LA1589). Genome 45:1189-1202

Duval M, Hsieh TF, Kim SY, Thomas TL (2002) Molecular characterization of AtNAM: a member of the Arabidopsis NAC domain superfamily. Plant Mol Biol 50:237-248

Falconer DS (1960) Introduction to quantitative genetics. R Mac Lehose and Com., Glasgow, pp 264-275

Foolad MR (1996) Response to selection for salt tolerance during germination in tomato seed derived from PI 174263. J Am Soc Hortic Sci 121:1006-1011

Foolad MR (1997) Genetic basis of physiological traits related to salt tolerance in tomato, Lycopersicon esculentum Mill. Plant Breed 116:53-58

Gilliam JW (1971) Rapid measurement of chlorine in plant materials. Soil Sci Soc Am Proc 35:512-513

Goldman IL, Paran I, Zamir D (1995) Quantitative trait locus analysis of a recombinant inbred line population derived from a Lycopersicon esculentum $\times$ Lycopersicon cheesmanii cross. Theor Appl Genet 90:925-932

Grandillo S, Tanksley SD (1996) QTL analysis of horticultural traits differentiating the cultivated tomato from the closely related species Lycopersicon pimpinellifolium. Theor Appl Genet 92:935-951

Grandillo S, Ku HM, Tanksley SD (1999) Identifying the loci responsible for natural variation in fruit size and shape in tomato. Theor Appl Genet 99:978-987

Greenway H, Munns R (1980) Mechanisms of salt tolerance in non-halophytes. Annu Rev Plant Physiol Plant Mol Biol 31:149-190

Hasegawa PM, Bressan RA, Zhu JK, Bohnert HJ (2000) Plant cellular and molecular responses to high salinity. Annu Rev Plant Physiol Plant Mol Biol 51:463-499

Infostat (2004) Infostat version 2004. FCA. Universidad Nacional de Córdoba, Argentina

Juenger TE, Sen S, Stowe KA, Simms EL (2005) Epistasis and genotype-environment interaction for quantitative trait loci affecting flowering time in Arabidopsis thaliana. Genetica 123:87-105

Khalf-Allah AM, Pierce LC (1963) A comparison of selection methods for improving earliness, fruit size and yield in tomato. Proc Am Soc Hortic Sci 82:414-419

Korstanje R, Paigen B (2002) From QTL to gene: the harvest begins. Nat Genet 31:235-236

Kosambi DD (1944) The estimation of map distance from recombination values. Ann Eugenetics 12:172-175

Lecomte L, Saliba-Colombani V, Gautier A, Gomez-Jimenez MC, Duffe P, Buret M, Causse M (2004) Fine mapping of QTLs of chromosome 2 affecting the fruit architecture and composition of tomato. Mol Breed 13:1-14
Lercher MJ, Urrutia AO, Hurst LD (2002) Clustering of housekeeping genes provides a unified model of gene order in the human genome. Nat Genet 31:180-183

Maas E, Hoffmann G (1977) Crop salt tolerance-current assessment. A.S.C.E 103

Malmberg RL, Held S, Waits A, Mauricio R (2005) Epistasis for fitness-related quantitative traits in Arabidopsis thaliana grown in the field and in the greenhouse. Genetics 171:20132027

Molinero-Rosales N, Jamilena M, Zurita S, Gomez P, Capel J, Lozano R (1999) FALSIFLORA, the tomato orthologue of FLORICAULA and LEAFY, controls flowering time and floral meristem identity. Plant J 20:685-693

Monforte AJ, Asins MJ, Carbonell EA (1997b) Salt tolerance in Lycopersicon species. 6. Genotype-by-salinity interaction in quantitative trait loci detection: constitutive and response QTLs. Theor Appl Genet 95:706-713

Monforte AJ, Asins MJ, Carbonell EA (1997a) Salt tolerance in Lycopersicon species. 5. Does genetic variability at quantitative trait loci affect their analysis? Theor Appl Genet 95:284-293

Monforte AJ, Asins MJ, Carbonell EA (1999) Salt tolerance in Lycopersicon spp. VII. Pleiotropic action of genes controlling earliness on fruit yield. Theor Appl Genet 98:593-601

Monforte AJ, Friedman E, Zamir D, Tanksley SD (2001) Comparison of a set of allelic QTL-NILs for chromosome 4 of tomato: deductions about natural variation and implications for germplasm utilization. Theor Appl Genet 102:572-590

Morgante M, Salamini F (2003) From plant genomics to breeding practice. Curr Opin Biotechnol 14:214-219

Munns R, Husain S, Rivelli AR, James RA, Condon AG, Lindsay MP, Lagudah ES, Schachtman DP, Hare RA (2002) Avenues for increasing salt tolerance of crops, and the role of physiologically based selection traits. Plant Soil 247:93-105

Ohto M, Onai K, Furukawa Y, Aoki E, Araki T, Nakamura K (2001) Effects of sugar on vegetative development and floral transition in arabidopsis. Plant Physiol 127:252-261

Owen PA, Nickell CD, Noel GR, Thomas DJ, Frey K (1994) Registration of saline soybean. Crop Sci 34:1689-1689

Paran I, Zamir D (2003) Quantitative traits in plants: beyond the QTL. Trends Genet 19:303-306

Paterson AH, Deverna JW, Lanini B, Tanksley SD (1990) Fine mapping of quantitative trait loci using selected overlapping recombinant chromosomes, in an interspecies cross of tomato. Genetics 124:735-742

Pérez-Alfocea F, Estan MT, Caro M, Bolarín MC (1993) Response of tomato cultivars to salinity. Plant Soil 150:203-211

Pérez-Alfocea E, Guerrier G, Estan MT, Bolarín MC (1994) Comparative salt responses at cell and whole-plant levels of cultivated and wild tomato species and their hybrid. J Hortic Sci 69:639-644

Sablowski RWM, Meyerowitz EM (1998) A homolog of NO APICAL MERISTEM is an immediate target of the floral homeotic genes APETALA3/PISTILLATA. Cell 92:93-103

Sacher RF, Staples RC, Robinson RW (1983) Ion regulation and response of tomato to sodium-chloride-a homeostatic system. J Am Soc Hortic Sci 108:566-569

Saliba-Colombani V, Causse M, Langlois D, Philouze J, Buret M (2001) Genetic analysis of organoleptic quality in fresh market tomato. 1. Mapping QTLs for physical and chemical traits. Theor Appl Genet 102:259-272

Santa-Cruz A, Perez-Alfocea F, Caro M, Acosta M (1998) Polyamines as short-term salt tolerance traits in tomato. Plant Sci 138:9-16

Steiner JJ, Banuelos GS (2003) Registration of ARS NLT-SALT and ARS-NLT-SALT/B saline tolerant narrow-leaf trefoil germplasm. Crop Sci 43:1888-1889 
Storey R, Walker RR (1999) Citrus and salinity. Sci Hortic 78:39_ 81

Tal M, Shannon MC (1983) Effects of dehydration and high-temperature on the stability of leaf membranes of Lycopersicon esculentum, L. cheesmanii, Lycopersicon. peruvianum and Solanum pennellii. Z Pflanzenphysiol 112:411-416

Tanksley SD (2004) The genetic, developmental, and molecular bases of fruit size and shape variation in tomato. Plant Cell 16:S181-S189

Thomas DSG, Middleton NJ (1993) Salinization-new perspectives on a major desertification issue. J Arid Environ 24:95-105

Van Ieperen W (1996) Effects of different day and night salinity levels on vegetative growth, yield and quality of tomato. J Hortic Sci 71:99-111

Van Ooijen JW, Maliepaard C (1996) MapQTL (tm) Version 3.0: Software for the calculation of QTL positions on genetic maps. DLO-Centre for Plant Breeding and Reproduction Research, Wageningen, The Netherlands
Van Ooijen JW, Voorrips R E (2001) Joinmap Version 3.0: Software for the calculation of genetic linkage maps $\mathrm{Re}$ lease 3.0. Plant Research International, Wageningen, The Netherlands

Van der Knaap E, Tanksley SD (2001) Identification and characterization of a novel locus controlling early fruit development in tomato. Theor Appl Genet 103:353-358

Verslues PE, Agarwal M, Katiyar-Agarwal S, Zhu JH, Zhu JK (2006) Methods and concepts in quantifying resistance to drought, salt and freezing, abiotic stresses that affect plant water status. Plant J 45:523-539

Villalta I, Reina-Sanchez A, Cuartero J, Carbonell EA, Asins MJ (2005) Comparative microsatellite linkage analysis and genetic structure of two populations of F-6 lines derived from Lycopersicon pimpinellifolium and L. cheesmanii. Theor Appl Genet 110:881-894

Xu GH, Magen H, Tarchitzky J, Kafkafi U (2000) Advances in chloride nutrition of plants. Adv Agronomy 68:97-150 